\title{
Los videojuegos en el proceso de aprendizaje de los niños de preescolar
}

\author{
Mónica María Córdoba Castrillón \\ Javier Ospina Moreno ${ }^{2}$
}

Recibido: 17-11-2018

Aceptado: 01-03-2019

\section{Resumen}

El uso de herramientas tecnológicas como apoyo en los procesos de enseñanza-aprendizaje de los niños de preescolar no debe visualizarse de forma negativa, todo lo contrario, para algunos autores el uso de software como juegos digitales o videojuegos, utilizados de forma moderada y adecuada resulta una estrategia positiva en el aprendizaje significativo de los niños. El objetivo general de la investigación es determinar la influencia de los juegos y los videojuegos en los procesos formativos de los estudiantes del nivel preescolar; y como objetivos específicos se definieron: conocer la relación juego-desarrollo cognitivo en los niños a través de los videojuegos o juegos digitales, indagar sobre la influencia de los videojuegos o juegos digitales en el proceso de enseñanza para los estudiantes del nivel preescolar, diseñar una herramienta tecnológica para propiciar una mejor relación juego-desarrollo cognitivo en el proceso de aprendizaje de los estudiantes del nivel preescolar. La orientación del diseño metodológico de la investigación corresponde a un estudio descriptivo-cuantitativo, no experimental, con toma de datos longitudinal; se seleccionó una población de 41 instituciones educativas públicas del municipio de

1. Administradora de empresas, especialista en gerencia educacional, magíster en administración de organizaciones. Corporación Universitaria Remington. Medellín - Colombia.

Correo electrónico: monica.cordoba@uniremington.edu.co

ORCID: https://orcid.org/0000-0002-8965-1146

2. Ingeniero de sistemas, especialista en gerencia de sistemas, magíster en gestión de la tecnología educativa. Corporación Universitaria Remington.

Medellín - Colombia.

Correo electrónico: Javier.ospina@uniremington.edu.co

ORCID: https://orcid.org/0000-0002-4168-3915 
Bello las cuales tienen nivel de preescolar. Se utilizaron dos tipos de instrumentos para la recolección de la información, la encuesta estructurada para recolectar información de los maestros de preescolar y entrevista a especialistas infantiles como pedagogos y psicólogos. Los resultados de este estudio permiten evidenciar, hacer uso de este tipo de herramientas tecnológicas de forma moderada y adecuada puede convertirse en un factor positivo en el proceso de aprendizaje de los niños de preescolar.

Palabras clave: preescolar, video juegos, juegos digitales, herramientas tecnológicas, lúdica, aprendizaje.

\title{
The video games in the learning process of preschool children
}

\begin{abstract}
The use of technological tools to support the teaching-learning processes of preschool children should not be seen negatively, on the contrary, for some authors the use of software such as digital games or video games, used in a moderate and appropriate way a positive strategy in the meaningful learning of children. The general objective of the research is to determine the influence of games and videogames on the formative processes of preschool students and as specific objectives were defined: to know the cognitive playdevelopment relationship in children through videogames or games digital, investigate the influence of video games or digital games in the teaching process for preschool students, design a technological tool to promote a better cognitive play-development relationship in the learning process of preschool students. The orientation of the methodological design of the research corresponds to a descriptive-quantitative study, not experimental, with longitudinal data collection; A population of 41 public educational institutions
\end{abstract}


of the municipality of Bello was selected, which have pre-school level. Two types of instruments were used for the collection of information, the structured survey to collect information from preschool teachers and interviews with child specialists such as pedagogues and psychologists. The results of this study make it possible to demonstrate, making use of this type of technological tools in a moderate and appropriate way can become a positive factor in the learning process of preschool children.

Keywords: preschool, video game, digital games, Technological tools, playful, learning.

\section{Introducción}

Es una realidad que los espacios campestres y verdes que anteriormente se utilizaba para el juego de los niños, hoy se han transformado en otro tipo de ambientes los cuales tienen que ver directamente con entornos virtuales. Ante esta realidad lo más importante es aprovechar las fortalezas que la tecnología ofrece (Aparicio, 2018), y hacer de estos nuevos entornos espacios efectivos para el aprendizaje significativo de los niños de preescolar, espacios que además permiten fomentar las dimensiones del desarrollo del ser humano desde el entorno familiar y escolar.

Para apoyar la investigación se utilizaron teorías como el juego en la etapa infantil, el juego en los procesos de aprendizaje en los niños de preescolar, el uso de Tecnologías de la Información y de la Comunicación en el preescolar y el impacto de los juegos digitales y videojuegos con los niños de preescolar desde el punto de vista de diferentes autores. En general, para algunos autores el juego es una necesidad y un derecho que tienen el ser humano, además debe ser una experiencia liberadora y motivante para la adquisición de habilidades en el desarrollo de las competencias intelectuales, sociales y morales. Los niños de hoy están acostumbrados 
a otros ambientes, son nativos digitales (Aparicio, 2018), nacieron y están creciendo rodeados de tecnología, algunos autores consideran esto como un proceso normal, pero, como todo equilibrio en la naturaleza, si se hace de forma prudente y moderada el uso de herramientas tecnológicas y de software como video juegos, resulta inofensivo en el proceso de aprendizaje de los niños del nivel de preescolar.

Los niños que habitan las aulas de las escuelas de hoy son diferentes, todo esto debido a las experiencias que plantea el mundo actual con la tecnología. Las metodologías que utilizan los maestros en su mayoría no los dirige de forma inmediata al mundo real en el que viven. ¿Incluir los juegos y los videojuegos en los procesos formativos puede generar un mejor desarrollo cognitivo en la generación digital? Con el desarrollo de la investigación se pretende demostrar y evidenciar cómo a través de la lúdica apoyada de las herramientas tecnológicas como video juegos, el aprendizaje de los niños de preescolar puede seguir siendo significativo y convertirse en un proceso variado, motivacional, en el que la familia pueda tener una participación activa para el fomento del crecimiento personal y comunitario, y se recuperen los valores y principios sociales que hagan de estos niños, hombres capaces de luchar por una sociedad sana y tranquila. El objetivo general de la investigación es determinar la influencia de los juegos y los videojuegos en los procesos formativos de los estudiantes del nivel preescolar. Como objetivos específicos se definieron: conocer la relación juego-desarrollo cognitivo en los niños a través de los videojuegos o juegos digitales, indagar sobre la influencia de los videojuegos o juegos digitales en el proceso de enseñanza para los estudiantes del nivel preescolar, diseñar una herramienta tecnológica para propiciar una mejor relación juego-desarrollo cognitivo en el proceso de aprendizaje de los estudiantes del nivel preescolar.

El desarrollo tecnológico es un proceso que avanza de forma acelerada y además aporta significativamente a todas las áreas del conocimiento; pero en ocasiones algunas personas consideran que el uso de herramientas tecnológicas hace perder el tiempo, desaprovechando el potencial que realmente tienen. El objetivo de esta 
investigación es determinar la influencia de los juegos y los videojuegos en los procesos formativos de los estudiantes del nivel preescolar, es decir, mostrar cómo desde el campo educativo iniciando desde el nivel preescolar con la utilización de un simple juego o videojuego se puede aprovechar el potencial que puede llegar a tener las herramientas tecnológicas, en los procesos de enseñanza- aprendizaje, y de esta forma generar una cultura de uso efectivo de medios y mediaciones tecnológicas con las generaciones digitales. Para el éxito de la investigación fue necesario abordar teorías que permitieran mostrar cómo desde la metodología del juego los infantes digitales pueden aprovechar de forma positiva el uso de videojuegos en sus procesos de aprendizaje significativo. Para este proceso fue necesario abordar teorías como son:

\section{Teoría sobre el juego en la etapa infantil}

El juego es una actividad que el ser humano desde su nacimiento realiza y además disfruta, pero al mismo tiempo contribuye a los procesos de desarrollo que, como ser social e individual, necesita para desenvolverse en su entorno. Según García, A., \& Llull, J. (2009) el juego es una actividad fundamental para el desarrollo y el aprendizaje en la infancia. El juego permitirá al niño poner en marcha los mecanismos de su imaginación, expresar su manera de ver el mundo que le rodea, desarrollar su creatividad y relacionarse con adultos e iguales. La actividad lúdica contribuye en gran medida a la maduración psicomotriz, potencia la actividad cognitiva, facilita el desarrollo afectivo y es vehículo fundamental para la socialización de los niños y niñas. Por eso, el juego se convierte en uno de los medios más poderosos que tienen los niños para aprender nuevas habilidades y conceptos a través de su propia experiencia.

Para Martínez, J. L. (2010) el juego constituye una herramienta indiscutible e inigualable en la evolución y progreso personal, en el sentido que propone el planteamiento psicomotor donde todos los aspectos e interacciones del individuo se gestionan de manera conjunta. A través del juego los niños tienen la posibilidad de 
expresar sus emociones y sentimientos y desarrollan todo tipo de habilidades que lo harán competentes en las diferentes disciplinas y aspectos vivenciales.

El juego, según algunos teóricos, no solo es una actividad que permite al niño distraerse, además, según Linaza, J. L. (2013) el juego es una necesidad, es reconocer la forma específica con la que los niños abordan la realidad, sea física, social o intelectual. Pero, en la medida en que es necesario para alcanzar nuestra condición humana, se convierte también en un derecho. Los niños tienen derecho al juego como expresión directa de su condición de menores, del mismo modo que no cabe imputarles la plena responsabilidad de sus actos hasta que no hayan disfrutado del tiempo ( ¿y las circunstancias?) necesarios en sus vidas para poder desarrollar tal responsabilidad, para hacerse adultos (Pérez, 2014).

El juego en los niños debe ser una actividad liberadora y espontanea, en ningún momento debe convertirse en una oportunidad que conlleve al castigo. Según García, C. (2015) en educación infantil, se debe tener en cuenta el juego no como una actividad de refuerzo o premio, sino como una actividad imprescindible, que debe ser realmente libre, espontánea y alegre para el niño, en la cual no se persigue ningún objetivo y no está sometido a unas reglas, y donde el adulto solo guie y observe sin orientar ni intermediar.

En general, según los anteriores autores, el juego en el niño no solo es una necesidad, también es un derecho que además permite su desarrollo integral. Para Extremera, A. B., \& Montero, P. J. R. (2016) el juego motor constituye un elemento pedagógico de primer orden, ayudando a desarrollar la capacidad creativa y una mejor comprensión de los conceptos intrínsecos que subyacen en el lenguaje. También, facilita el desarrollo de los diferentes aspectos de la personalidad del niño/a, del carácter, habilidades sociales, dominios motores y capacidades físicas. Además, ofrece gran variedad de experiencias que facilita la adaptación y la autonomía. 


\section{Teoría sobre el juego en los procesos de aprendizaje en los niños de preescolar}

El juego en los niños según diferentes autores es una actividad que conlleva al desarrollo cognitivo, psicosocial, individual y físico. Permite al niño expresarse libre y de forma creativa, pero principalmente permite adquirir de forma lúdica habilidades que lo llevaran al logro de competencias. Para Montealegre, R., \& Forero, L. A. (2006) el juego en los procesos de lecto-escritura al igual que los gestos, el garabato y el dibujo son las primeras construcciones con características simbólicas. Por medio del juego experimental en el que se representan cosas y personas con objetos familiares, se construye una breve narración interpretada por gestos figurativos sobre los objetos. En la situación de juego se designa, por ejemplo, un libro abierto como una casa, unas llaves como niños, un lápiz representando la niñera, etc., y a continuación se representa la narración involucrando los objetos, que son manipulados con gestos representativos de acuerdo a su papel en la historia. Los resultados demuestran que los niños de tres años pueden entender fácilmente una narración simbólica de estructura sencilla, y niños de cinco años comprenden narraciones mucho más complejas (de Almeida, Santos, Porto, 2017).

En la educación preescolar, la actividad del juego contribuye en procesos, tal como lo plantean Reséndiz, E., Correa, S., Medina, K., Nava, C., \& Llanos, R. (2014), la resolución de problemas que contribuyen al uso del conteo, así como el uso de los números en la vida cotidiana, lo cual llevará a entender que una serie de objetos no cambia solo por el hecho de dispersarlos. En el nivel preescolar el niño aprende el concepto del número como el resultado de un conteo que le permitirá conocer el número de objetos que posee, o el número de juguetes que podrá compartir con sus amigos o compañeros de clase y de esta forma aprende el significado del número y lo que él representa en su proceso de socialización.

El proceso de aprendizaje en los niños de preescolar es un proceso cotidiano basado en actividades lúdicas y vivenciales, que le 
permitirán prepararse para la etapa escolar según Moreno, C. X. G., Solovieva, Y., \& Rojas, L. Q. (2014) en la edad preescolar el niño adquiere conceptos cotidianos (empíricos), de manera inmediata por medio del contacto físico, durante su participación en diversas actividades como los juegos, los paseos, la actividad práctica y artística.

Otro factor importante del juego en los niños de preescolar es el relacionamiento con su familia y con sus maestros, González, Y. B., \& Mendoza, Y. M. (2015) opinan si los padres y educadores son capaces de observar a su hijo teniendo en cuenta que el juego es su vida, empezarán a ver el juego de una forma bien distinta a su creencia de que éste es pura diversión o una enfermedad del propio infante. Un juego educativo que hayamos comprado, puede no ser divertido y, si no hay diversión, difícilmente habrá aprendizaje. El infante sabe bien lo que le gusta y lo que no, y no le convenceremos de lo contrario. Es por tanto un preciado medio de educación, de ahí la importancia que reviste la preparación a la familia para el óptimo aprovechamiento de las potencialidades que este brinda en la formación desde edades tempranas de las nuevas generaciones (Tahull, 2016).

Según Chacón (citado por Jiménez, J. M., \& Araya, Y. C. 2012) las investigaciones apoyan el papel fundamental que el juego posee en el desarrollo socioemocional, cognitivo y físico del niño, así como en la regulación de las emociones, el fortalecimiento de las relaciones sociales con los miembros de su familia y amigos, en la atención, en la resolución de problemas, en la creatividad y en el desarrollo de destrezas motoras gruesas y finas, así como en su salud en general.

\section{Teoría sobre uso de Tecnologías de la Información y de la Comunicación en el preescolar}

Mucho se habla sobre si es apropiado o no utilizar herramientas tecnológicas para el proceso de enseñanza-aprendizaje con los niños de preescolar según lo plantea Ortiz Vargas, S. N., \& Pérez Díaz, L. K. (2015) se constata las bondades de los recursos tecno- 
lógicos dentro del aula y específicamente en transición y da un claro ejemplo de las transformaciones que se pueden llevar a cabo con ayuda de los recursos tecnológicos, en cuanto a competencias propias del preescolar como lo son las dimensiones del desarrollo humano. Para López Araujo, M. A. (2013) en las horas de clase los niños cumplen con muchas actividades para desarrollar diferentes destrezas, cuando asisten al laboratorio de informáticas, aunque no sepan leer y escribir, los niños desarrollan competencias en el uso de manejo de herramientas tecnológicas buscan gráficos, íconos con colores llamativos y representaciones con personajes.

Para algunos el uso de herramientas tecnológicas en niños de preescolar puede resultar preocupante, pero según Paniagua-Esquivel, C., Alfaro, R., \& Fornaguera, J. (2016) se ha propuesto que es posible re direccionar su uso del computador en pro del aprendizaje, introduciéndola como un elemento cotidiano, como un instrumento de comunicación, de adquisición de información y para favorecer la interacción social.

Cabe destacar que las herramientas tecnológicas pueden resultar inofensivas con los niños de preescolar si se enfocan tal y como lo plantea Leyva, J. T., Pineda, V. O., Valencia, R. E. C., \& Oregón, M. G. (2013) es evidente la importancia de crear situaciones de interacción de los niños de nivel preescolar con la tecnología, generar una cultura de tecnología bien estructurada, hacer énfasis en el dinamismo implícito en los medios electrónicos, pero sobre todo demostrar que la informática es una herramienta eficaz para el apoyo en el proceso enseñanza/aprendizaje.

Para Sluis et al. 2004, Khandelwal \& Mazalek 2007 y Tyng et al. 2011 (citados por Nácher, 2014), demuestran que la tecnología puede ser utilizada por niños con edades entre tres y siete años para aprender habilidades de lectura, resolver problemas matemáticos, desarrollar el sentido del espacio, etc. Además, diversos estudios demuestran que esta tecnología también proporciona importantes resultados en la promoción de la colaboración entre compañeros y a la hora de fomentar su creatividad. 
Argumenta Camargo, D. M., \& Orozco, L. C. (2013). Por otra parte, reconociendo que es imposible detener la dinámica mundial relacionada con el acceso y uso de este tipo de dispositivos, en la actualidad se plantea la necesidad de utilizar los medios en forma positiva, para incrementar los hábitos alimenticios saludables y las conductas prosociales, y para disminuir el consumo de alcohol, el de tabaco y la iniciación temprana de relaciones sexuales. Además, se propone la necesidad de educar a los padres para controlar no solo el tiempo, sino el contenido y la calidad de los programas de televisión y de las redes de información a las que acceden sus hijos, así como de implementar normas en los hogares para su utilización, siguiendo las recomendaciones de las organizaciones internacionales.

\section{Teoría sobre el impacto de los juegos digitales y videojuegos con los niños de preescolar}

Para Jiménez, J. M., \& Araya, Y. C. (2012) un videojuego es un programa informático en el que el usuario o jugador mantiene una interacción a través de imágenes que aparecen en un dispositivo que posee una pantalla que puede variar de tamaño. Además, existe un sistema de clasificación de los juegos de acuerdo con su contenido y que de alguna forma nos permite conocer el público al que supuestamente están dirigidos, así como los posibles riesgos de su utilización (Entertainment Software Rating Board, 2010). Esta clasificación se realiza por medio de letras de la siguiente manera: EC («early childhood»): son videojuegos con contenidos temáticos para niños de 3 años. No contiene material que los padres puedan considerar inapropiado.

González, M. O. A. G., Magaña, M. F. F., Gutiérrez, E. C., Jiménez, P. Y. J. M., \& Pérez, P. A. C. P. aclaran que el juego de hoy, ha dejado atrás las áreas verdes, los campos deportivos, y los parques, para dar lugar a ambientes virtuales presentes en juegos de video y de computador. 
Según Dixon, M. NiMhurchu, J. Meagher, L. \& Widdowson (citado por Jiménez, J. M., \& Araya, Y. C. 2012) existe evidencia que indica que tanto los padres como los hijos consideran que los videojuegos activos promueven la actividad física y pueden contribuir a reducir la obesidad infantil. Para Jiménez, J. M., \& Araya, Y. C. (2012) jugar un videojuego activo es más beneficioso que ser sedentario. Sin embargo, los videojuegos activos son más beneficiosos que los videojuegos pasivos, pero vale la pena decir el juego tradicional y el proporcionado por los videojuegos seguirá siendo importante en todas las etapas del desarrollo de niños y adolescentes.

Plantea Solórzano Castro, B. A. (2015) existe un sin número de software diseñados para el nivel inicial, los mismos que comprenden actividades que utilizadas de manera adecuada y en espacios propicios no solo desarrollarían y fortalecerían habilidades y destrezas, sino que, también darían la oportunidad de fomentar valores y hábitos de convivencia escolar, ya que los niños y las niñas aprenderían de manera divertida a socializar, compartir y a respetar a través de juegos, canciones y demás actividades que generan el aprendizaje significativo.

Según Barrantes Morales, R. M. (2016) el potencial pedagógico de las TIC para el desarrollo integral de los niños y niñas de preescolar, a través del diseño e implementación de IntegraTIC, un ambiente virtual de aprendizaje (AVA) basado en los principios de la educación preescolar: lúdico, integral y holístico y los principios del conectivismo: autónomo, interactivo, diverso y abierto (AIDA). El marco de referencia está dado por, las orientaciones curriculares para preescolar, el conectivismo y las dimensiones del desarrollo del ser humano.

En el caso de Jiménez, M. D. L. Á. C., Mora, M. P., \& Trías, J. F. (2013) los Ambientes Virtuales Colaborativos, los niños y niñas se enfrentan a juegos virtuales en los que deben resolver problemas de manera conjunta. La meta u objetivo del juego solo puede alcanzarse si los niños trabajan juntos, utilizando diferentes interfaces (ratón, teclado, etc.). De esta manera, se propicia la socializa- 
ción, el desarrollo cognitivo y la alfabetización tecnológica, entre otros (MEP y Fundación Omar Dengo, 2011).

Según López, L. E. G. (2015), los niños de hoy han crecido con la presencia natural de las nuevas tecnologías en su vida cotidiana. Para ellos, los juegos de video, los equipos de sonido, los computadores y otros aparatos electrónicos, no revisten ningún misterio; se aproximan a éstos sin temor y los exploran con sorprendente facilidad. Por ello, la utilización del computador como herramienta de escritura puede llegar a ser algo tan natural como el garabateo que espontáneamente hace un niño cuando se le presta un lápiz. De igual forma opinan Castillo, V. S., Cano, C. A. G., Polanía, D. O., Gallego, T. A. C., \& Rondón, L. P. V. (2016) los videojuegos deben ser vistos como una forma de invasión de las TIC a la sociedad, que también tiene efectos sobre el sistema educativo, los cuales pueden ser utilizados como una herramienta lúdica integral (Morales, 2009; Pascual, 2013).

Afirman Cárdenas Muriel, M., Burgos, C., Mahúm, J., \& Orozco Rojas, Y. A. (2016) que la multimedia ayuda a que los niños y niñas se familiaricen y se apropien de las TICS estimulando así la capacidad visomotora y psicomotora de los niños y las niñas, la lectoescritura, la iniciación al conocimiento lógico, la lúdica y la creatividad mediados por los juegos digitales. Los niños de hoy están acostumbrados a entornos diferentes y el hecho de estar rodeados de tecnología no los hace menos capaces de socializar y de establecer relacionamiento con las personas que los rodean.

\section{Metodología}

La orientación del diseño metodológico de la investigación corresponde a un estudio descriptivo-cuantitativo, no experimental, con toma de datos longitudinal; se seleccionó una población de 41 instituciones educativas públicas del municipio de Bello las cuales tienen nivel de preescolar, a un nivel de confianza del 95\%, margen de error de $5 \%$, valores probabilísticos de p 0.7 y q 0.1 . Los valores 
de p y q para el cálculo de la muestra se encontraron por prueba piloto, con estos parámetros se realizó dicho cálculo y arrojó como resultado 30. Se utilizaron dos tipos de instrumentos para la recolección de la información, en primer lugar, se diseñó una encuesta estructurada para recolectar información de los maestros de preescolar y posteriormente se aplicó la técnica de la entrevista a especialista infantiles como pedagogos y psicólogos, para estos últimos la muestra fue definida de manera selectiva por criterio (por conveniencia) con un total de 50 especialistas. Los datos fueron recolectados por los investigadores y el estudio se realizó en el año de 2017.

\section{Resultados}

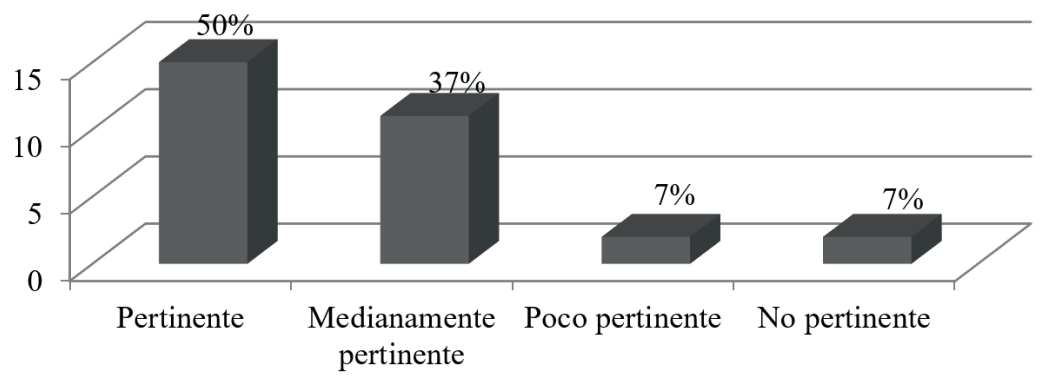

Figura 1. Los videos juegos como apoyo al proceso de enseñanza-aprendizaje. Fuente. Elaboración de los autores.

La figura 1 permite evidenciar la opinión de los maestros de preescolar con respecto al uso de video juegos como apoyo al proceso de enseñanza-aprendizaje, para lo cual el $50 \%$ de la población encuestada consideran que resulta pertinente y medianamente pertinente lo cual significa que están de acuerdo en que es una experiencia que no tiene incidencias negativas en los procesos cognitivos de los niños. 


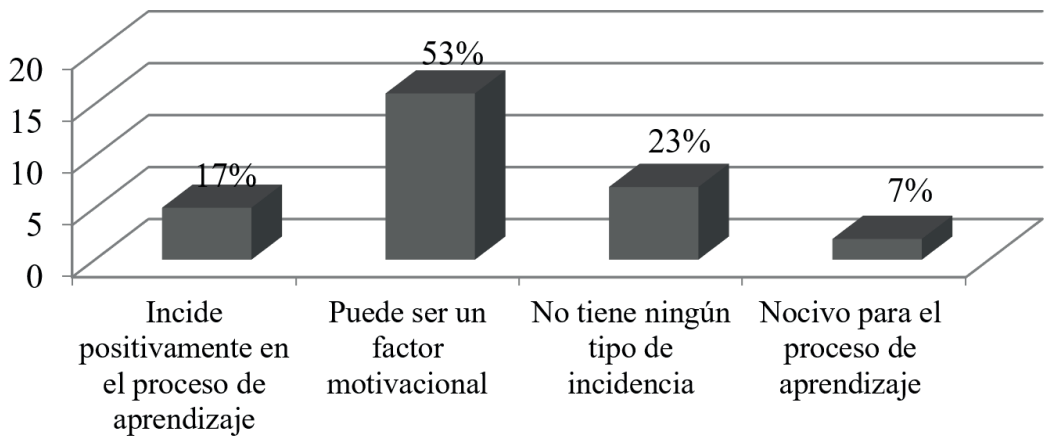

Figura 2. Articulación de los procesos tradicionales de aprendizaje con los juegos virtuales.

Fuente. Elaboración de los autores.

Se evidencia en la figura 2 que en un alto porcentaje de especialistas infantiles opinan que el complementar los procesos tradicionales con juegos virtuales en las clases con los niños puede ser un factor motivacional que incida positivamente en el aprendizaje de los niños de preescolar, debido a que estas mediaciones son elementos de su vida cotidiana.

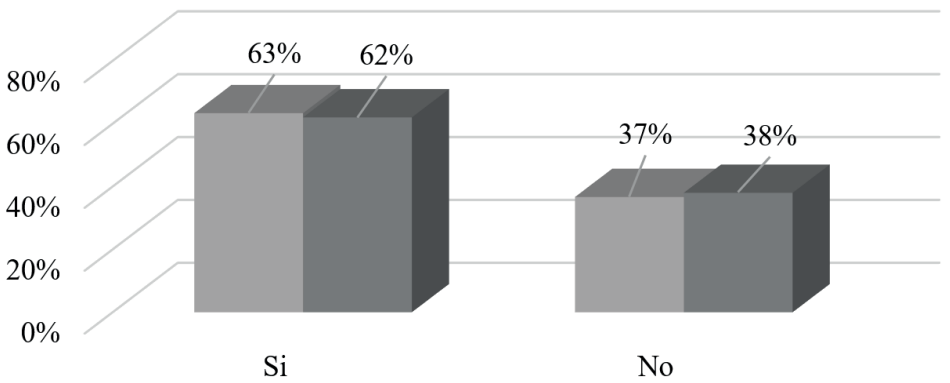

\section{Maestros $\square$ Especialistas}

Figura 3. Conocimiento de juegos digitales que ayudan al proceso de aprendizaje de los niños. Fuente. Elaboración de los autores.

La figura 3 muestra cómo los maestros y los especialistas coinciden en que existen juegos digitales que realmente contribuyen o ayudan en el proceso de aprendizaje de los niños. Lo que significa que las herramientas tecnológicas pueden ser una estrategia de apoyo para los maestros en el aula de clase. 


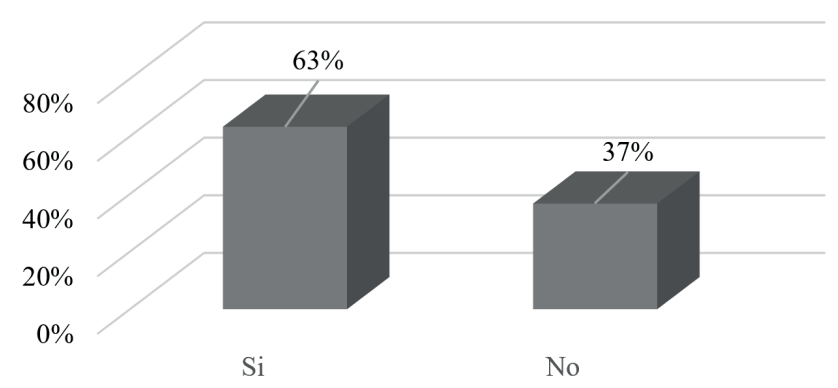

Figura 4. Frecuencia del uso de videojuegos o juegos virtuales en sus clases. Fuente. Elaboración de los autores.

La figura 4 permite evidenciar que un alto porcentaje de maestros de los maestros encuestados hace uso frecuente de herramientas tecnológicas como videojuegos como complemento de sus estrategias didácticas.

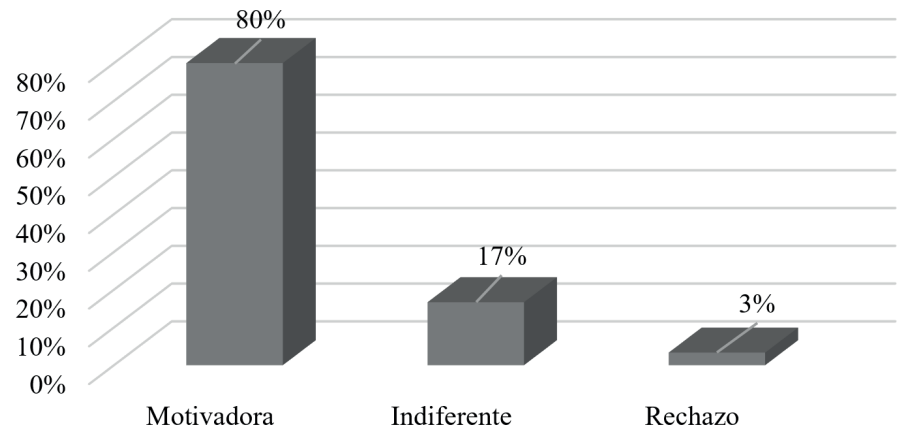

Figura 5. Actitud de los niños frente al uso de videojuegos en la clase.

Fuente. Elaboración de los autores.

Teniendo en cuenta los maestros que utilizan videojuegos y juegos virtuales en sus clases, se puede evidenciar en la figura 5 que la actitud de los niños frente a este tipo de herramientas en clase en un alto porcentaje es motivadora, lo que hace que el maestro pueda tener un amplio portafolio de elementos para que el niño sienta grandes deseos y necesidad de aprender. 


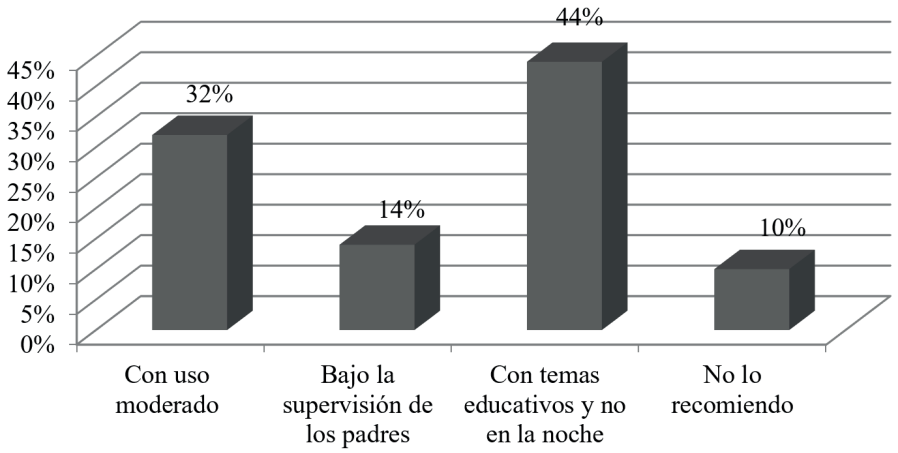

Figura 6. Recomienda para los niños el uso de videojuegos en casa.

Fuente. Elaboración de los autores.

La figura 6 permite evidenciar que el $90 \%$ de los especialista está de acuerdo en que los niños pueden utilizar videojuegos en casa, teniendo en cuenta que debe hacerse con uso sea moderado, bajo la supervisión de los padres, con fines educativos y no practicar estos juegos en horas de la noche, solo el $10 \%$ de la población encuestada que equivale a 5 especiales plantea que no recomienda utilizar este tipo de juegos en casa ya que puede desviar la atención de los niños con respecto al relacionamiento familiar.

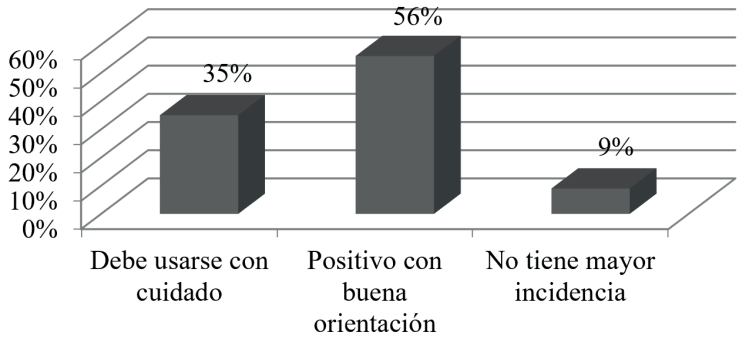

Figura 7. Impacto de la tecnología en los niños de preescolar.

Fuente. Elaboración de los autores.

Con la figura 7 se puede evidenciar la coincidencia de opiniones entre los teóricos que apoyan la investigación y entre los especialistas infantiles a quienes se les aplicó la entrevista, para ambos su opinión inciden en que el uso de herramientas tecnológicas debe ser utilizado con buena orientación y precaución de lo contrario puede resultar nocivo para el aprendizaje de los niños, solo un por- 
centaje bajo de la población encuestada opina que no tiene mayor incidencia en los procesos de aprendizaje de los niños.

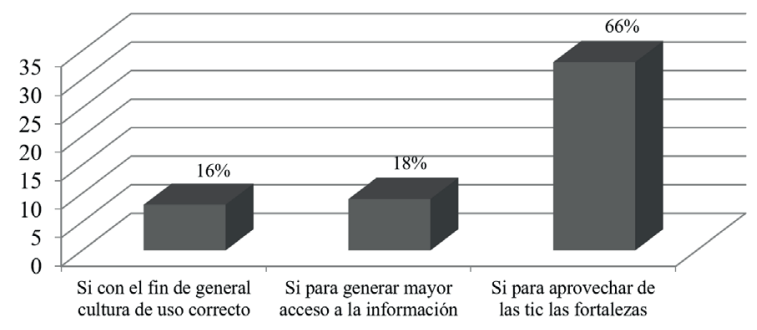

Figura 8. ¿Deben las escuelas hacer transformaciones curriculares integrando las TIC?

Fuente. Elaboración de los autores.

La figura 8 muestra la opinión de los especialistas infantiles con respecto a si deben hacer o no las escuelas transformaciones curriculares incluyendo las TIC como herramientas de apoyo al proceso de enseñanza-aprendizaje, el $100 \%$ de los especialistas entrevistados opinan que si es importante que la escuela haga transformaciones curriculares ya que lo ven como una oportunidad para generar cultura de uso correcto y efectivo, además porque es una realidad que facilitan el acceso a la información y permite que los maestros tengan mayores oportunidades de varias sus estrategias didácticas.

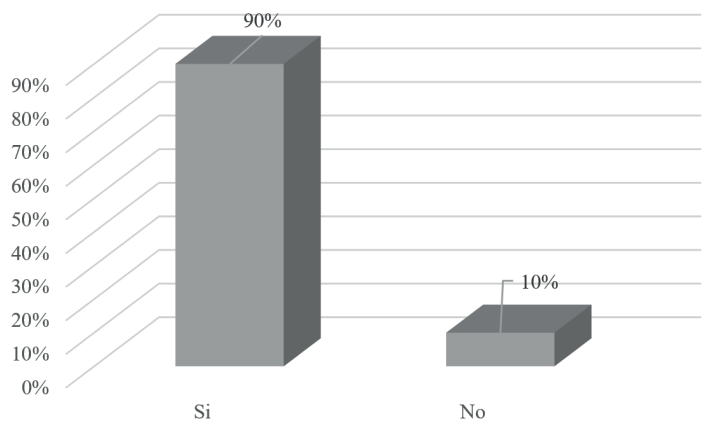

Figura 9. Considera importante tener como apoyo en sus clases una plataforma educativa basada en juegos. Fuente. Elaboración de los autores.

La figura 9 permite evidenciar que el $90 \%$ de los maestros encuestados le dan importancia al hecho de tener una plataforma educativa basada en juegos como apoyo a sus clases, mientras que 
el 10\% que equivale a 3 maestros consideran que no es importante, teniendo en cuenta que en Colombia desde el año 2013 se publicó el documento "Competencias TIC para el Desarrollo Profesional Docente", el cual se enfoca en la necesidad de formar a los maestros con el fin de transformar sus prácticas educativas con el apoyo de las TIC (MEN, 2013).

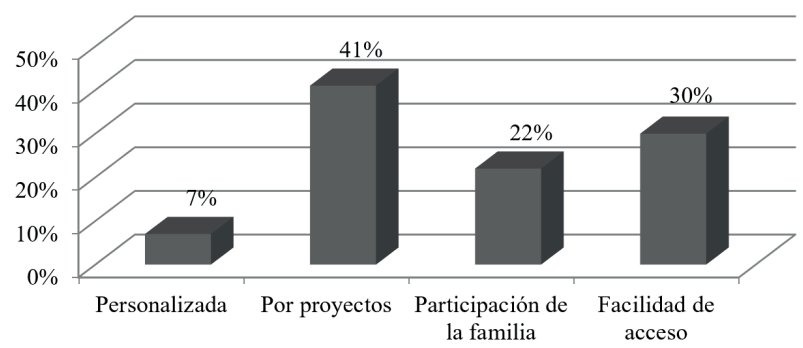

Figura 10. ¿Qué elementos tendría una plataforma que ayude a mejorar los procesos de aprendizaje de los estudiantes del nivel preescolar? Fuente. Elaboración de los autores.

Con la figura 10 se evidencia los elementos que los maestros consideran importantes que debe tener una plataforma de apoyo para los procesos de aprendizaje para los niños de preescolar, siendo los más relevantes: que este organizada por proyectos, además que sea de fácil acceso ya que los niños al inicio del nivel no saben leer ni escribir lo que implica que la plataforma debe ser intuitiva, diseñada para trabajar con la participación de la familia y personalizada para que cada niño pueda conocer sus avances en el proceso de aprendizaje (Ortiz, Buitrago, 2017).

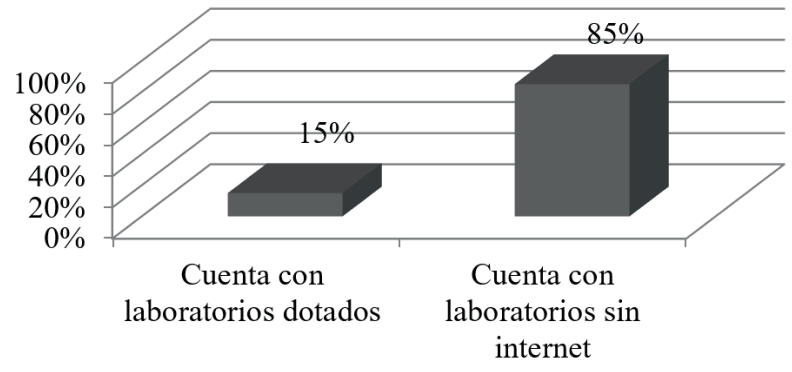

Figura 11. La institución cuenta con laboratorios de informática dotados para el uso de una plataforma educativa. Fuente. Elaboración de los autores. 
La figura 11, muestra todas las instituciones educativas cuenta con laboratorios de informática, pero un alto porcentaje no cuenta con internet lo que implica que es necesario generar estrategias que permitan que los maestros de preescolar puedan hacer uso de plataformas sin necesidad de internet, según MINTIC (2012) el país debe superar diversas barreras para lograr la masificación del Internet, en infraestructura, servicios, aplicaciones, usuarios.

\section{Discusión}

Para autores como Balerdi, F. E. (2001) y Jiménez, J. M., \& Araya, Y. C. (2012) los videojuegos utilizados por los niños son motivo de preocupación debido a que pueden generar efectos negativos en lo que respecta a actitudes violentas, aspectos psicológicos y fisiológicos, pero si bien es cierto los sistemas educativos en los diferentes países del mundo día a día buscan evolucionar en este tipo de procesos, existe una preocupación generalizada por vigilar y culturizar a los actores que intervienen en el proceso formativo de los niños; lo que implica que la solución no es prohibir ni satanizar la tecnología, todo lo contrario utilizarla de forma positiva ya que para los nativos digitales hace parte de su ambiente cotidiano.

Los juegos digitales o videojuegos tienen una característica importante que influye positivamente en los procesos de aprendizaje de los niños y es su ambiente gráfico y dinámico, la combinación de imágenes, colores, sonido, movimiento hacen que el niño por intuición identifique objetos, números, letras y pueda establecer relaciones sin ni siquiera saber leer y escribir, de ahí la opinión de los maestros de preescolar y de los expertos infantiles utilizar ambientes diseñados con fines educativos, donde el juego y el conocimiento combinados le permitan al niño aprender de forma dinámica y divertida, teniendo en cuenta que las herramientas por si solas no tienen ningún impacto, pero articuladas en algunos momentos de la clase y en los momentos de trabajo independiente con la familia, resultan efectivas para el proceso de aprendizaje de los niños (Aparicio \& Ostos, 2018). 
Existe una relación directa entre el juego y el desarrollo cognitivo de los niños, ya que el juego es una actividad fundamental y conlleva al aprendizaje, el niño a través del juego pone en marcha su imaginación y desarrolla su creatividad, los videojuegos o juegos digitales permiten que el niño se enfrente a diferentes situaciones en las cuales requiere no solo de su imaginación, también la necesidad de trabajar en equipo y de esta forma facilitar el desarrollo afectivo, otro aspecto importante de los videojuegos o juegos digitales es la posibilidad de abordar la realidad, aportando a soluciones de forma tranquila, que faciliten para el niño en sus procesos de adaptación y autonomía (Konieczny, 2015).

Los videojuegos o juegos digitales tienen gran influencia en los niños en etapa preescolar, si bien es cierto si no se trabaja con responsabilidad puede resultar nocivo en los procesos de aprendizaje, en primer lugar no es aconsejable el uso de herramientas digitales en horas de la tarde ya que pueden entorpecer el sueño del niño, otro aspecto importante a tener en cuenta es que el maestro no debe abusar del uso de estas herramientas en clase, si bien es cierto hacen más motivante el proceso de aprendizaje del niño, es necesario enseñar el uso adecuado y moderado de estás, a nivel familiar no es recomendable que el niño trabaje solo con dispositivos que le permitan acceder a videojuegos o juegos digitales, ya que puede perderse la intencionalidad del juego el cual vela por fomentar las dimensiones del desarrollo del ser humano.

Finalmente, para los niños de hoy la presencia de la tecnología y todo lo que ella conlleva con respecto a ambientes virtuales es natural para ellos y de uso cotidiano, por lo tanto, hablar sobre la influencia que tienen los videojuegos o juegos digitales en el proceso de aprendizaje ya no es un paradigma, lo importante es a través de ellos fomentar valores y hábitos de convivencia escolar y generar aprendizaje significativo. De ahí la importancia de diseñar ambientes de aprendizaje digital por proyectos, de fácil acceso para los niños, con actividades no solo para trabajar en la clase, también que permita la integración de las familias (Ferreyra, 2014) y permitiendo generar informes personalizados donde el niño pueda conocer sus procesos de desarrollo e información individual. 


\section{Conclusiones}

Para los maestros y especialistas infantiles que participaron en la investigación es tranquilo reconocer la influencia positiva que los videojuegos y juegos digitales ejercen en el proceso de aprendizaje de los niños de preescolar, ya que los niños de hoy han crecido con la presencia natural de la tecnología, lo importante de este fenómeno es enseñar a los niños a través de la escuela y la familia el uso adecuado de los videojuegos y juegos digitales y aprovechando de ellos el impacto positivo para fomentar las dimensiones del desarrollo del ser humano.

Según los expertos realmente existen videojuegos y juegos digitales que conllevan al niño a procesos de aprendizaje significativo, ambientes en los cuales hay mezcla de imágenes, sonido, videos, colores y otros elementos resultan ser divertidos y atractivos, además permiten que el niño pueda ser creativo y desarrolle su imaginación, trabajando de forma individual y en equipo, aportando soluciones a situaciones reales que a través del juego impacten positivamente en el proceso cognitivo de los niños.

Tener una plataforma digital de juegos como herramienta de apoyo para el proceso de enseñanza con los niños de preescolar, es una estrategia valiosa para los maestros, su diseño debe estar fundamentado en el desarrollo de proyectos, que sea de fácil acceso para los niños es decir intuitiva ya que los niños en este nivel apenas inician con el proceso de lecto-escritura, importante que permita el trabajo con la familia y personalizada para que cada niño se sienta cómodo y familiarizado en el ambiente virtual. También sería importante para los maestros tener una plataforma que no requiera totalmente de internet ya que existe un número significativo de instituciones educativas que incluso hoy no cuentan con laboratorios informáticos dotados con todo lo necesario para hacer uso de las bondades que ofrece la Web.

El juego cumple un papel fundamental en el desarrollo socioemocional, cognitivo y físico del niño, pero también a través del 
juego el niño puede aprender a regular sus emociones y a establecer relaciones sociales con su familia y amigos. Hoy con los videojuegos o juegos digitales se pueden simular situaciones (escolares, familiares, sociales) en las cuales el niño con sus compañeros de clase, maestros y familia desarrollen su creatividad aportando soluciones y de forma tranquila pueda trabajar la tolerancia incluso al fracaso.

\section{Referencias bibliográficas}

Aparicio, O.Y. (2018). Las TIC como herramientas cognitivas. Revista Interamericana de Investigación, Educación y Pedagogía, RIIEP, 11(1). https://orcid.org/0000-0003-3535-6288

Aparicio, O.Y. (2018). Las TIC como herramientas cognitivas para la investigación escolar. Revista Interamericana de Investigación, Educación y Pedagogía, RIIEP, 11(1). https://orcid.org/0000-0003-3535-6288

Aparicio, O.Y., \& Ostos, O.L. (2018). El constructivismo y el construccionismo. Revista Interamericana de Investigación, Educación y Pedagogía, RIIEP, 11(2). https://orcid.org/0000-0003-3535-6288. https://orcid.org/0000-0002-6477-9872

Balerdi, F. E. (2001). Videojuegos y educación. Education in the knowledge society (EKS), (2), 3. Web:http://revistas.usal.es/index.php/ revistatesi/article/view/14154

Barrantes Morales, R. M. (2016). Integratic a nuevos saberes y expresiones. Un ambiente virtual de aprendizaje para el desarrollo integral de los niños y niñas del grado preescolar. Web: https://intellectum.unisabana. edu.co/handle/10818/25950

Camargo, D. M., \& Orozco, L. C. (2013). Factores asociados a la disponibilidad y uso de medios electrónicos en niños desde preescolar hasta $4^{\circ}$ grado. Biomédica, 33(2), 175-185. Web: http://www.redalyc. org $/ \mathrm{html} / 843 / 84328377003 /$

Cárdenas Muriel, M., Burgos, C., Mahúm, J., \& Orozco Rojas, Y. A. (2016). La multimedia como herramienta lúdico pedagógica en el currículo de 
informática del nivel preescolar, contribuye a desarrollar principios de integralidad, participación y esparcimiento. Web: http://repository. libertadores.edu.co/handle/11371/452

Castillo, V. S., Cano, C. A. G., Polanía, D. O., Gallego, T. A. C., \& Rondón, L. P. V. (2016). Percepción Social Importancia del Inglés e Inclusión de Videojuegos como Herramienta de Aprendizaje. Amazonia Investiga, 5(8).Web: http://www.udla.edu.co/revistas/index.php/amazoniainvestiga/article/view/519

de Almeida, R. R., Santos, M. F., \& Porto, J. C. (2017). Lectura de textos ficcionales y el enfoque escolar de literatura: contribuciones para una Pedagogía de la Elección. Revista Interamericana de Educación, Pedagogía y Estudios Culturales, 9(1), 35-51. DOI: https://doi. org/10.22490/25391887.1925

Extremera, A. B., \& Montero, P. J. R. (2016). El juego motor como actividad física organizada en la enseñanza y la recreación. EmásF: revista digital de educación física, (38), 73-86. Web: https://dialnet. unirioja.es/servlet/articulo?codigo $=5351993$

Ferreyra, H. A. (2014). Mesas Socioeducativas para la Inclusión y la Igualdad. Un programa "De todos con todos". Una experiencia en construcción. Revista Interamericana de Investigación, Educación y Pedagogía, RIIEP, 7(2). DOI: https://doi.org/10.15332/s1657107X.2014.0002.01

García, A., \& Llull, J. (2009). El juego infantil y su metodología. Madrid: Editex. Web: http://revistapulso.cardenalcisneros.es/documentos/ articulos/110.pdf.

García, C. (2015). El juego libre en la creación musical de 3 a 6 años. Web: http://uvadoc.uva.es/handle/10324/15840.

González, M. O. A. G., Magaña, M. F. F., Gutiérrez, E. C., Jiménez, P. Y. J. M., \& Pérez, P. A. C. P. Videojuegos y aprendizaje: análisis sobre el uso de videojuegos como materiales de aprendizaje significativo. Web: http:// www.archivos.ujat. $\mathrm{mx} /$ dip/divulgacion $\% 20 \mathrm{y} 20$ video\%20cinetifico\%20 2008/DAIS/AGonzalezG.pdf 
González, Y. B., \& Mendoza, Y. M. (2015). Acciones educativas para la preparación de la familia en el desarrollo de juegos en el hogar. Lecturas: Educación física y deportes, (202), 2. Web: https://dialnet.unirioja.es/ servlet/articulo?codigo $=5575661$.

Hernández Suarez, C. A., Arévalo Duarte, M. A., Suarez, G., \& Aloiso, A. (2016). Competencias TIC para el desarrollo profesional docente en educación básica. Praxis \& Saber, 7(14), 41-69. Web: http://www.scielo. org.co/pdf/prasa/v7n14/v7n14a03.pdf.

Jiménez, J. M., \& Araya, Y. C. (2012). El efecto de los videojuegos en variables sociales, psicológicas y fisiológicas en niños y adolescentes. Retos: nuevas tendencias en educación física, deporte y recreación, (21), 43-49. Web: http://www.redalyc.org/html/3457/345732287009/.

Jiménez, M. D. L. Á. C., Mora, M. P., \& Trías, J. F. (2013). Introducción de tecnologías en el aula de dos preescolares públicos costarricenses: estrategias de autogestión, alcances y limitaciones. Revista Electrónica" Actualidades Investigativas en Educación", 13(2), 1-23. Web: http:// www.scielo.sa.cr/pdf/aie/v13n2/a06v13n2.

Konieczny, P. (2015). Lorenzo García Aretio: bases, mediaciones y futuro de la educación a distancia en la sociedad digital. Revista Interamericana de Investigación, Educación y Pedagogía, RIIEP, 8(1). DOI: https://doi. org/10.15332/s1657-107X.2015.0001.08

Leyva, J. T., Pineda, V. O., Valencia, R. E. C., \& Oregón, M. G. (2013). Educando a los nativos digitales de preescolar con apoyo de herramientas didácticas de software libre. Vínculos, 10(2), 421-434. Web: http:// revistas.udistrital.edu.co/ojs/index.php/vinculos/article/view/6565.

Linaza, J. L. (2013). El juego es un derecho y una necesidad de la infancia. Bordón. Revista de Pedagogía. Web: https://repositorio.uam. es/handle/10486/662399.

López Araujo, M. A. (2013). Creación de recursos interactivos en lectura para niños de educación preescolar del colegio Thomas Jefferson, utilizando técnicas de ilustración y animación digital. Web: http://200.24.220.94/handle/33000/3710. 
López, L. E. G. (2015). El computador en el aula de preescolar: una herramienta más de escritura. Revista Educación y Pedagogía, 14 (33), 167-175. Web: http://aprendeenlinea.udea.edu.co/revistas/index.php/ revistaeyp/article/view/24798

Martínez, J. L. (2010). Jugar por jugar. El juego en el desarrollo psicomotor y en el aprendizaje infantil. Educatio Siglo XXI, 28(1), 349-351. Web: http://revistas.um.es/educatio/article/viewFile/109881/104541

MINISTERIO DE EDUCACIÓN NACIONAL. (2013). Competencias TIC para el desarrollo profesional docente. Bogotá: MEN. Web: https://www. mineducacion.gov.co/1759/w3-article-339097.html.

MINISTERIO DE LAS TECNOLOGÍAS DE LA INFORMACIÓN Y LA COMUNICACIÓN. (2012). La formación de docentes en TIC, casos exitosos de Computadores para Educar. Bogotá: MINTIC. Web: http:// apps.cpe.gov.co/LibroDigital/pages/formacion_docentesTIC.pdf

Montealegre, R., \& Forero, L. A. (2006). Desarrollo de la lectoescritura: adquisición y dominio. Acta colombiana de psicología, 9(1), 25-40. Web: http://www.redalyc.org/pdf/798/79890103.pdf

Moreno, C. X. G., Solovieva, Y., \& Rojas, L. Q. (2014). El juego temático de roles sociales: aportes al desarrollo en la edad preescolar. Avances en Psicología Latinoamericana, 32(2), 287-308. Web: http://www.redalyc. org/html/799/79930906008/.

Nácher Soler, V. E. (2014). Estudio de las capacidades motoras de niños en edad preescolar para la realización de gestos en superficies multitáctiles. Web: https://riunet.upv.es/handle/10251/37129.

Ortiz, J. G., \& Buitrago, H. (2017). La evaluación en la tradición educativa colombiana. Instrumento de clasificación social. Revista Interamericana de Investigación, Educación y Pedagogía, RIIEP, 10(1), 145-171. DOI: https://doi.org/10.15332/s1657-107X.2148

Ortiz Vargas, S. N., \& Pérez Díaz, L. K. (2015). Análisis de la apropiación de las TIC en los docentes en nivel de transición de las instituciones educativas privadas del municipio de Barbosa, Santander (Doctoral dissertation, Universidad Pedagógica y Tecnológica de Colombia). Web: http://repositorio.uptc.edu.co/handle/001/1411. 
Paniagua-Esquivel, C., Alfaro, R., \& Fornaguera, J. (2016). Aporte docente en el diseño de Ambientes Virtuales Colaborativos para educación preescolar. Ciencia, Docencia y Tecnología, 27(52). Web: http://www.scielo.org.ar/scielo.php?script=sci_arttext\&pid =S1851-17162016000100016

Pérez, T. H. (2014). Colombia: de la educación en emergencia hacia una educación para el posconflicto y la paz. Revista Interamericana de Investigación, Educación y Pedagogía, RIIEP, 7(2). DOI: https://doi. org/10.15332/s1657-107X.2014.0002.06

Reséndiz, E., Correa, S., Medina, K., Nava, C., \& Llanos, R. (2014). La enseñanza aprendizaje del número en preescolar y el uso de las TIC's. Web: http://funes.uniandes.edu.co/6185/

Solórzano Castro, B. A. (2015). Las ntic's y su impacto en la educación de los niños y niñas en edad preescolar del centro Integral del buen vivir Sonrisitas del barrio Mariscal Sucre, cantón La Libertad, provincia Santa Elena, período lectivo 2013-2014. Web: http://repositorio.upse.edu.ec/ handle/46000/2341

Tahull, J. (2016). Modernidad, educación y género. El proyecto inacabado. Revista Interamericana de Investigación, Educación y Pedagogía, RIIEP, 9(2), 159-178. DOI: https://doi.org/10.22490/25391887.1947

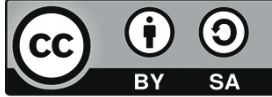

